Muideen T. Olaiya, MSc Dominique A. Cadilhac, $\mathrm{PhD}$

Joosup Kim, PhD Mark R. Nelson, PhD

Velandai K. Srikanth, $\mathrm{PhD}$

Nadine E. Andrew, PhD

Christopher F. Bladin,

PhD, FRACP

Richard P. Gerraty, MD, FRACP

Sharyn M. Fitzgerald, $\mathrm{PhD}$

Thanh Phan, PhD Judith Frayne, MBBS,

FRACP

Amanda G. Thrift, PhD

On behalf of the

STANDFIRM (Shared

Team Approach

Between Nurses and

Doctors for Improved

Risk Factor

Management)

Investigators

Correspondence to

Dr. Thrift:

amanda.thrift@monash.edu

Supplemental data at Neurology.org

\section{Long-term unmet needs and associated factors in stroke or TIA survivors}

\author{
An observational study
}

\section{ABSTRACT}

Objective: To extensively investigate long-term unmet needs in survivors of stroke or TIA and to identify factors associated with these unmet needs.

Methods: Community-dwelling adults were invited to participate in a survey $\geq 2$ years after discharge for stroke/TIA. Unmet needs were assessed across 5 domains: activities and participation, environmental factors, body functions, post-acute care, and secondary prevention. Factors associated with unmet needs were determined with multivariable negative binomial regression.

Results: Of 485 participants invited to complete the survey, 391 (81\%) responded (median age 73 years, $67 \%$ male). Most responders (87\%) reported unmet needs in $\geq 1$ of the measured domains, particularly in secondary prevention (71\%). Factors associated with fewer unmet needs included older age (incident rate ratio [IRR] 0.62, 95\% confidence interval [CI] 0.50-0.77), greater functional ability (IRR $0.33,95 \% \mathrm{Cl} 0.17-0.67)$, and reporting that the general practitioner was the most important in care (IRR 0.69, 95\% Cl 0.57-0.84). Being depressed (IRR 1.61, 95\% Cl 1.23-2.10) and receiving community services after stroke (IRR 1.45, 95\% Cl 1.161.82) were associated with more unmet needs.

Conclusions: Survivors of stroke/TIA reported considerable unmet needs $\geq 2$ years after discharge, particularly in secondary prevention. The factors associated with unmet needs could help guide policy decisions, particularly for tailoring care and support services provided after discharge. Neurology ${ }^{\circledR}$ 2017;89:68-75

\section{GLOSSARY}

$\mathbf{C I}=$ confidence interval; $\mathbf{G P}=$ general practitioner; IRR $=$ incident rate ratio; STANDFIRM $=$ Shared Team Approach Between Nurses and Doctors for Improved Risk Factor Management.

Similar to other countries, survivors of stroke in Australia often experience long-term disability, ${ }^{1,2}$ resulting in profound difficulties and needs after discharge. ${ }^{3,4}$ In one recent study, $84 \%$ reported unmet needs at a median of 2 years after stroke. ${ }^{3}$ This may significantly affect survivors' ability to carry out normal activities ${ }^{5,6}$ or to cope with ongoing care needs, including routine review of post-acute care and secondary prevention. ${ }^{7}$

Previous surveys on long-term unmet needs were focused on needs resulting from functional deficits after stroke such as the management of body functions, participation in daily activities, or needs induced by new social/environmental factors. ${ }^{3,4,8,9}$ Consequently, data regarding unmet needs specifically related to critical aspects of long-term management such as post-acute care and secondary prevention are scarce. These 2 aspects deserve serious consideration in the overall assessment of unmet needs in survivors of not only stroke but also TIA. Moreover, demographic factors and the presence of certain disabilities/health problems have been associated with longterm unmet needs. ${ }^{3,4,8,9}$ However, opportunity exists to explore previously unreported factors, especially those related to care and support services provided to survivors after hospital discharge.

From Stroke and Ageing Research (M.T.O., D.A.C., J.K., V.K.S., N.E.A., T.P., A.G.T.), Department of Medicine, School of Clinical Sciences at Monash Health, Monash University, Clayton; Stroke Division (D.A.C., J.K., N.E.A.), Florey Institute of Neuroscience and Mental Health, Heidelberg; Menzies Institute for Medical Research (M.R.N., V.K.S.), Hobart; Department of Epidemiology and Preventive Medicine (M.R.N., S.M.F.), Monash University, Melbourne; School of Medicine (M.R.N.), University of Tasmania, Hobart; Department of Neurosciences (C.F.B.), Box Hill Hospital; Department of Medicine (R.P.G.), Epworth Healthcare, Monash University, Richmond; and Department of Neurology (J.F.), Alfred Hospital, Melbourne, Australia.

STANDFIRM Coinvestigators are listed at Neurology.org.

Go to Neurology.org for full disclosures. Funding information and disclosures deemed relevant by the authors, if any, are provided at the end of the article. 
Table 1 Areas covered by the domains of needs assessed

\begin{tabular}{|c|c|c|c|c|}
\hline Body functions ${ }^{a}$ & $\begin{array}{l}\text { Activities and } \\
\text { participation }\end{array}$ & Environmental ${ }^{\mathrm{a}}$ factors & Secondary prevention & Post-acute care \\
\hline $\begin{array}{l}\text { Urination and } \\
\text { defecation }\end{array}$ & Mobility & $\begin{array}{l}\text { Community organization } \\
\text { services }\end{array}$ & Education on stroke & Organization of care \\
\hline Sensation of pain & Speech & $\begin{array}{l}\text { Home adaptation, design, } \\
\text { and reconstruction }\end{array}$ & Use of medications & Individualization of care \\
\hline Fatigue & Recreation and leisure & Social support services & Goal setting & $\begin{array}{l}\text { Participation in decision } \\
\text { making }\end{array}$ \\
\hline Emotion & $\begin{array}{l}\text { Social and family } \\
\text { relationships }\end{array}$ & Social Security services & Self-management & \\
\hline \multicolumn{5}{|l|}{ Memory } \\
\hline Vision & & & & \\
\hline
\end{tabular}

${ }^{a}$ Mapped to the International Classification of Function core sets for stroke and neurologic conditions for post-acute care.

In this study, we extensively investigated long-term unmet needs in communitydwelling survivors of stroke/TIA across several domains, including post-acute care and secondary prevention, at $\geq 2$ years after discharge. We also identified factors associated with these unmet needs.

METHODS Study design and participants. The present study was an exit survey conducted in participants who completed participation in the Shared Team Approach Between Nurses and Doctors for Improved Risk Factor Management (STANDFIRM), a randomized controlled trial of risk factor management in survivors of stroke/TIA. Details of the trial design, including participant recruitment, have been described previously. ${ }^{10}$ Briefly, participants were recruited from 4 tertiary referral hospitals in Melbourne, Australia, between January 2010 and November 2013. Eligible participants were adults (age $\geq 18$ years) hospitalized for stroke/ TIA. Exclusion criteria were enrollment in another trial, admission from/discharge to a nursing home, or presence of cognitive disorder or worsening health condition. Participants who completed 2 years of follow-up in the STANDFIRM trial were eligible for the present study; thus, participants who died or were lost during follow-up were excluded.

Standard protocol approvals, registrations, and patient consents. Ethics approval was obtained (Human Research Ethics Committee No. 2011000331), and written informed consent was provided by all participants. The STANDFIRM trial is registered with the Australian New Zealand Clinical Trials Registry (ACTRN12608000166370).

Questionnaire design. A 48-item semistructured, selfadministered questionnaire was developed to assess unmet needs. The expected time of completion was $\leq 20$ minutes. Approximately $70 \%$ of items in this questionnaire aligned directly with a prior Australian study, ${ }^{3}$ with questions developed by an expert advisory group and reviewed by survivors of stroke, stroke researchers, and representatives from Australia's Stroke Foundation and general practice. These questions had good content validity $^{3}$ and great consistency with those asked in a previous UK study. ${ }^{4}$ The remaining items (30\%) were developed by the STANDFIRM investigators and were specifically targeted at domains of need related to post-acute care and secondary prevention.

Data collection. Questionnaires were mailed to eligible participants with the use of a modified Dillman ${ }^{11}$ protocol. Briefly, the questionnaire was posted as part of a package that also contained a certificate of participation, a letter of thanks for participating, and an invitation to participate in the exit survey. A postage-paid return envelope was attached to facilitate return of the questionnaire. Participants were advised to contact our research office if they preferred to complete the survey by telephone.

If there was no response within 3 weeks after the survey was sent, participants were sent a second follow-up letter, together with the questionnaire and a postage-paid return envelope. Attempts were made to contact participants via telephone if there was still no response within 3 weeks of sending the second questionnaire. During the follow-up call, participants were asked whether they would prefer being sent another survey or completing the survey by telephone. If a participant was unable to be contacted at the initial telephone follow-up, another attempt was made within the following 2 weeks, after which no further attempts were made. Nonresponders successfully contacted by telephone were not contacted again.

Demographic information and details of stroke, including preexisting comorbidities and discharge destination, were obtained from medical records at baseline. At the 24-month follow-up, trained assessment nurses obtained self-reported data on living status and details of care and services received after discharge. Nurses also undertook standardized assessment of cardiovascular risk ${ }^{12}$ and mental and functional status. ${ }^{13,14}$ Baseline and 24-month data were collected separately as part of the STANDFIRM trial.

Outcome measure. The main outcome was the total number of unmet needs self-reported at $\geq 2$ years after discharge. An unmet need was defined in a context similar to previous studies as "a need of something or help from someone (that would help overcome some of the effects of stroke and resulting difficulties) that is not being met." ${ }^{\prime, 4}$ Overall, 30 unmet needs were assessed across 5 domains. Twenty unmet needs were mapped to domains of management of body functions, activities and participation, or 
Table 2 Characteristics of the study cohort who responded to survey and those who did not respond

\begin{tabular}{|c|c|c|c|}
\hline & $\begin{array}{l}\text { Nonresponders } \\
(\mathrm{n}=94), \mathrm{n}(\%)\end{array}$ & $\begin{array}{l}\text { Responders } \\
(\mathrm{n}=391), \mathrm{n}(\%)\end{array}$ & p Value \\
\hline \multicolumn{4}{|l|}{ Demographics } \\
\hline Age $\geq 65 y$ at stroke onset & 43 (46.2) & 247 (63.3) & 0.003 \\
\hline Male & $60(63.8)$ & $262(67.0)$ & 0.560 \\
\hline Born in Australia & $57(60.6)$ & $245(62.7)$ & 0.717 \\
\hline Married/living with partner & 60 (63.8) & 265 (67.8) & 0.468 \\
\hline Vocational/higher education & 52 (55.3) & 207 (52.9) & 0.678 \\
\hline High socioeconomic position ${ }^{a}$ & $42(44.7)$ & $198(50.6)$ & 0.299 \\
\hline \multicolumn{4}{|l|}{ Medical history at baseline } \\
\hline \multicolumn{4}{|l|}{ Type of stroke } \\
\hline Ischemic stroke & 74 (78.7) & $308(78.8)$ & 0.821 \\
\hline Intracerebral hemorrhage & $8(8.5)$ & $27(6.9)$ & \\
\hline TIA & $12(12.8)$ & $56(14.3)$ & \\
\hline Recurrent stroke & 13 (13.8) & 51 (13.0) & 0.841 \\
\hline \multicolumn{4}{|c|}{ Length of hospitalization for stroke } \\
\hline Median (Q1, Q3), d & $4(2,6)$ & $3(2,6)$ & 0.082 \\
\hline$\leq 3 \mathrm{~d}$ of hospital stay & $52(55.9)$ & $170(43.6)$ & 0.032 \\
\hline$\geq 2$ Comorbidities $^{b}$ & 50 (53.2) & 205 (52.4) & 0.894 \\
\hline Discharged to rehabilitation & 35 (37.6) & $120(30.7)$ & 0.207 \\
\hline \multicolumn{4}{|l|}{ Health and living status at $24 \mathrm{mo}$} \\
\hline $\begin{array}{l}\text { Median Framingham CVD } \\
\text { risk (Q1-Q3) }\end{array}$ & $17.7(10.6-28.5)$ & $22.2(12.2-34.4)$ & 0.192 \\
\hline $\begin{array}{l}\text { Disability, median LHS } \\
\text { score (Q1-Q3) }\end{array}$ & $0.83(0.67-0.97)$ & $0.89(0.79-1.00)$ & 0.003 \\
\hline Depressed (HADS score $>7$ ) & $17(18.1)$ & 44 (11.3) & 0.085 \\
\hline Anxious (HADS score $>7$ ) & 20 (21.3) & $52(13.4)$ & 0.063 \\
\hline Living alone & $16(17.0)$ & 83 (21.2) & 0.355 \\
\hline
\end{tabular}

Abbreviations: CVD = cardiovascular disease; HADS = Hospital Anxiety and Depression Scale; LHS = London Handicap Scale; Q = quartile.

Data are expressed as frequency and proportion unless otherwise stated.

a Determined with Australian Socio-Economic Indexes for Areas using postal codes.

${ }^{b}$ Comorbidities include history of diabetes mellitus, hypertension, dyslipidemia, or atrial fibrillation. construct validity of survey questions, factor analyses were undertaken with Kaiser criterion. ${ }^{16}$ For the main outcome analyses, participants with $\geq 10 \%$ of outcome data missing were excluded. Participants with $\geq 30 \%$ of outcome data missing in a domain were excluded from analyses of that domain. Manual backward stepwise multivariable-negative binomial regression analyses were used to determine factors associated with unmet needs because this regression model shows a better fit (than Poisson regression model) for overdispersed outcome data. ${ }^{17}$ Variables tested for inclusion in the model were those obtained at baseline (demographic factors, details of stroke, and preexisting comorbidities) and at 24 months (living status, measures of health status, and care and services received after discharge). Time between hospitalization for stroke and return of survey and use of a care/management plan (the STANDFIRM intervention) were also incorporated. Variables were systematically eliminated until a suitable model was obtained. Apart from age and sex, only variables with a value of $p<0.05$ were retained in the final models. To investigate any potential bias arising from the exclusion of missing outcome data, 3 separate multivariable models (sensitivity analyses) were undertaken, including multiple imputation of missing data and replacing missing observations with extreme values of 0 or 1 . Potential interactions between logical combinations of variables were investigated by inserting interaction (cross-product) terms into multivariable models and checking any differences between models with or without interaction terms, based on a value of $p<0.05$ in likelihoodratio tests. All analyses were conducted with STATA IC (12.0; StataCorp, College Station, TX). A 2-sided $p$ value $<0.05$ was considered statistically significant.

RESULTS Participant characteristics. Among 485 participants who completed the STANDFIRM trial, 391 (81\%) responded to the exit survey, 77 (16\%) were uncontactable, $4(1 \%)$ were not interested, and 9 (2\%) did not participate for other reasons (figure e-1 at Neurology.org). Responses were provided directly by participants (65\%), their relatives (16\%), or caregivers or friends/associates (1\%), while for $18 \%$, this information was not provided. Only 1 participant provided responses via telephone. Overall, 126 participants $(33 \%)$ returned an incomplete survey. Responders had a median age of 73 (quartile 1, 63; quartile 3, 81) years, and 67\% were male. The median time since stroke was 32 (quartile 1, 29; quartile 3, 40) months.

Compared with nonresponders, responders were more often $\geq 65$ years of age at stroke onset $(63 \%$ vs $46 \%, p=0.003$ ) and had less disability (median London Handicap Scale score 0.89 vs $0.83, p=$ 0.003 ) at 24 months (table 2).

Outcome analyses. Main outcome analyses included 376 responders $(96 \%)$ with $<10 \%$ of outcome data missing. Overall, participants reported a median of 5 (quartile 1, 1; quartile 3, 10) unmet needs; $87 \%$ reported unmet needs in at least 1 of the 5 domains (table 3), and 56\% reported $\leq 5$ unmet needs (figure e-2). Results were similar for ischemic stroke $(88 \%)$, intracerebral hemorrhage $(85 \%)$, and TIA 
Table 3 Unmet needs at $\geq 2$ years after discharge by stroke type

\begin{tabular}{|c|c|c|c|c|c|c|}
\hline Domain of unmet needs & $\begin{array}{l}\text { All cases } \\
(n=391), n(\%)\end{array}$ & $\begin{array}{l}\text { IS or ICH } \\
(n=335), n(\%)\end{array}$ & $\begin{array}{l}\text { IS }(n=308), \\
n(\%)\end{array}$ & $\begin{array}{l}\mathrm{ICH}(n=27), \\
n(\%)\end{array}$ & $\begin{array}{l}\text { TIA ( } n=56) \\
n(\%)\end{array}$ & $p$ Value $^{a}$ \\
\hline Total & $326(86.7)$ & $283(87.6)$ & 261 (87.9) & 22 (84.6) & $43(81.1)$ & 0.354 \\
\hline Post-acute care & $192(49.4)$ & $169(50.6)$ & $154(50.2)$ & 15 (55.6) & 23 (41.8) & 0.416 \\
\hline Secondary prevention & 276 (70.9) & 242 (72.5) & 224 (73.0) & 18 (33.3) & 34 (61.8) & 0.228 \\
\hline Body functions & $230(59.7)$ & $200(60.6)$ & $182(59.9)$ & 18 (69.2) & $30(54.6)$ & 0.445 \\
\hline
\end{tabular}

Abbreviations: $\mathrm{ICH}=$ intracerebral hemorrhage; IS = ischemic stroke.

a Difference among survivors of ischemic stroke, intracerebral hemorrhage, and TIA.

${ }^{\mathrm{b}} \mathrm{p}<0.05$.

(81\%, $p=0.354)$. Health-related unmet needs (secondary prevention, body functions, and postacute care) were the most commonly reported (table 3 and table e-1). The proportion of proxy respondents reporting unmet needs (94\%) was greater than the proportion of direct respondents $(84 \%, p=0.026)$, but respondents with proxies had greater disability (table e-2).

For factor analyses, 4 uncorrelated factors, accounting for $66 \%$ of variations in outcome data, were extracted on the basis of eigenvalues $\geq 1$. Structures of these factors showed $71 \%$ to $80 \%$ consistency with those proposed previously (table 1$).{ }^{15}$ However, some factor loadings could not be explained, which limited the use of these analyses to support the survey questions.

Figure 1 Multivariable stepwise-negative binomial regression analysis of factors associated with total number of unmet needs at $\geq 2$ years after discharge

Incidence rate ratio, $95 \% \mathrm{Cl}^{*}$

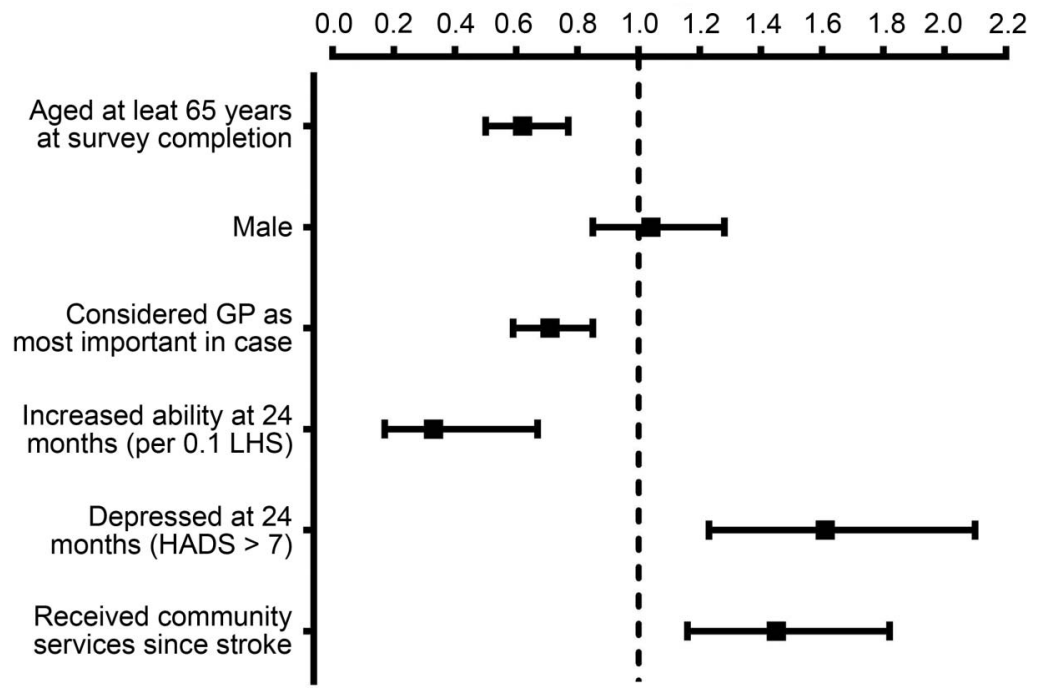

$\mathrm{Cl}=$ confidence interval; GP = general practitioner; HADS = Hospital Anxiety and Depression Scale; LHS = London Handicap Scale. *Model adjusted for all the variables listed in table e-2.
Univariable-negative binomial regression analyses of factors associated with unmet needs are presented in table e-3. In stepwise multivariable analyses, factors associated with fewer unmet needs at $\geq 2$ years after discharge included being $\geq 65$ years of age (incident rate ratio [IRR] $0.62,95 \%$ confidence interval [CI] $0.50-0.77$ ), greater functional ability (IRR 0.33 , 95\% CI 0.17-0.67), and reporting the general practitioner (GP) as the most important health professional involved in care (IRR 0.69, 95\% CI 0.57-0.84; figure 1). In contrast, being depressed (IRR 1.61, 95\% CI 1.23-2.10) and receiving community services after stroke (IRR 1.45, 95\% CI 1.161.82) were associated with more unmet needs. These variables, along with educational attainment, were similarly associated with unmet needs across most of the domains (table 4). A trend was also observed between use of rehabilitation and more unmet needs (table e-4). There were no significant interactions of variables in multivariable models. Estimates from our sensitivity analyses, involving imputation of missing outcome data, were consistent with the unimputed model (data not shown).

DISCUSSION We report a comprehensive assessment of long-term unmet needs in survivors of stroke/TIA that specifically incorporates domains of needs related to critical aspects of long-term management of stroke such as post-acute care and secondary prevention. A major finding is that survivors of stroke/TIA have considerable long-term unmet needs after discharge. Indeed, a large proportion of our participants reported unmet needs in at least 1 of the 5 investigated domains. Unmet needs were most prominent in the domain of secondary prevention, an area of need rarely reported.

The proportion of participants reporting unmet needs $(87 \%)$ is less than that $(96 \%)$ in a previous Australian survey, ${ }^{3}$ despite $70 \%$ of questions overlapping. However, similar to our study, unmet needs were more often reported in health-related domains 
Table 4 Multivariable stepwise regression analysis of factors associated with unmet needs at $\geq 2$ years after discharge according to the measured domains

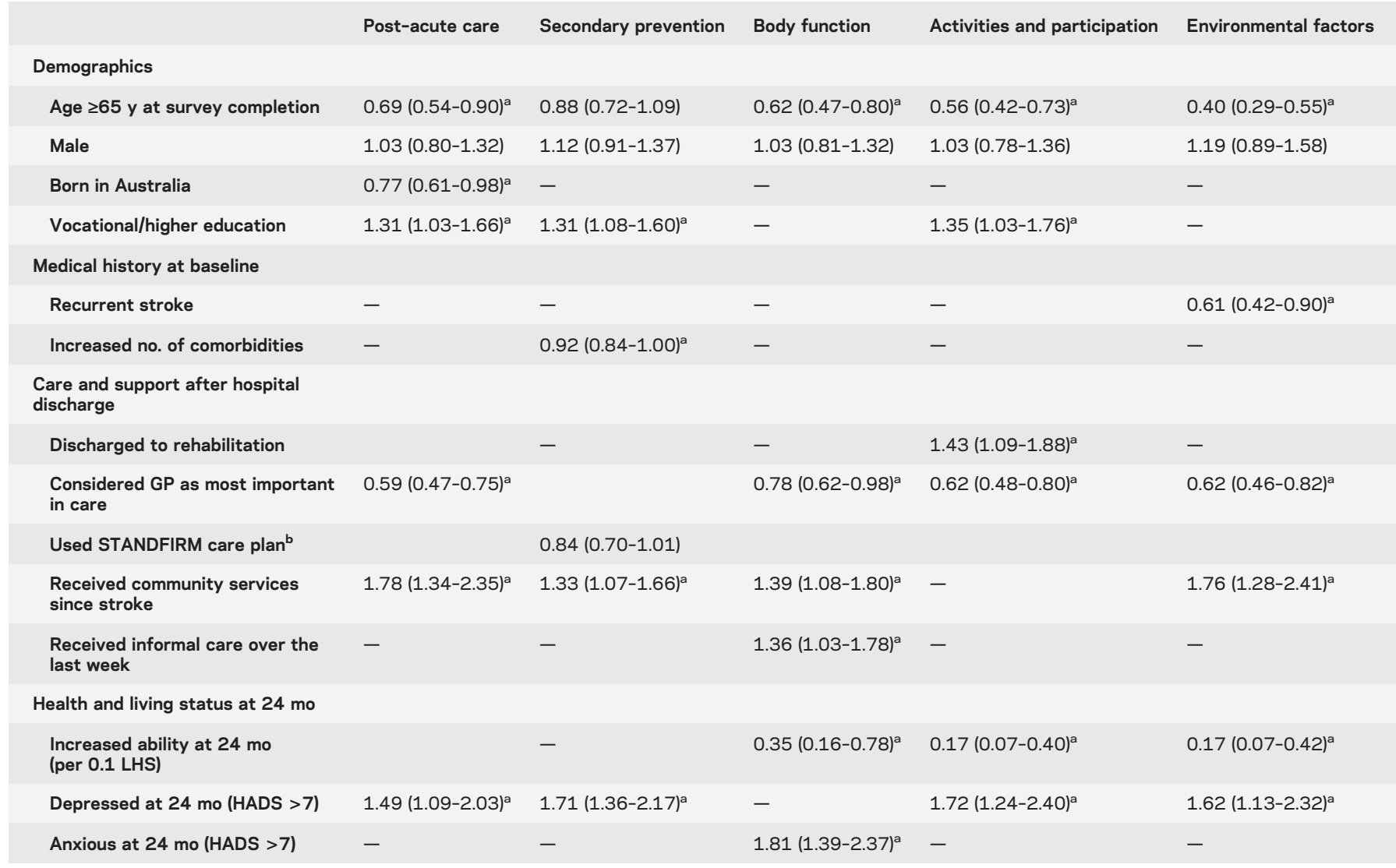

Abbreviations: GP = general practitioner; HADS = Hospital Anxiety and Depression Scale; LHS = London Handicap Scale; STANDFIRM = Shared Team Approach Between Nurses and Doctors for Improved Risk Factor Management.

All estimates are expressed as incidence rate ratio (95\% confidence interval).

Full regression models consisted all variables listed in table e- 2 .

${ }^{a} p<0.05$.

${ }^{\mathrm{b}}$ Comprised 3 nurse-education sessions and regular review of an individualized care plan by a multidisciplinary team.

in the previous survey. Our comparatively smaller proportion of participants reporting unmet needs may be explained by our recruitment of participants from a metropolitan region with better access to medical care. In contrast, recruitment in the prior study was from both metropolitan and rural areas.

In the United Kingdom, smaller proportions of community-based survivors of stroke reported unmet needs, $49 \%$ in older (average age 69 years) ${ }^{4}$ and $70 \%$ in younger (average age 57 years) age groups. ${ }^{18}$ It is important to acknowledge that our findings may not be directly comparable to these UK studies as a result of differences in survey items, definition/categorization of unmet need, and time of assessment. However, despite these limitations in comparability, these findings highlight a consistent, clear need for systems that could better support survivors in the community.

The observed similarity in unmet needs across stroke type potentially reflects the full context of conditions of survivors of stroke/TIA. Although functional deficits are largely influenced by stroke type, other factors such as comorbidities may contribute to the spectrum of needs after stroke/TIA. ${ }^{19}$ Indeed, preexisting comorbidities appeared similarly common between our survivors of stroke and survivors of TIA (table e-5), thereby justifying our approach to combine these groups in outcome analyses.

Another major finding was the considerable unmet needs reported in the domain of secondary prevention. We were unable to detect an association between the use of the STANDFIRM intervention and unmet needs of secondary prevention. This is surprising because the STANDFIRM intervention comprised robust strategies for secondary prevention, including 3 tailored nurse-education sessions, and regular multidisciplinary review of the care plan. ${ }^{10}$ Clearly, more effective interventions are needed to address unmet needs related to secondary prevention.

We further report rare data on factors associated with long-term unmet needs in survivors of stroke/ TIA, especially those related to care and support services available to survivors after discharge. Report of 
a GP being the most important health professional involved in care was associated with fewer unmet needs in each of the 5 domains. This could be attributed to the presence of policy options in Australia that facilitate better engagement of GPs in coordinating services to support continuing recovery of patients with complex needs such as stroke. ${ }^{20}$ Similarly, receiving community services after stroke was associated with more unmet needs overall and in most of the measured domains, indicating that available services may not be specifically or sufficiently meeting needs of survivors.

The observed association between educational attainment and more unmet needs may reflect greater expectations of well-educated patients regarding treatment outcomes/general recovery, ${ }^{21}$ with attendant disappointment when expectations are unmet. Our finding on the association between depression and more unmet needs was also unsurprising. Mood disorders are often inadequately assessed in hospital settings, ${ }^{22}$ and access to psychological services is usually limited after acute care. ${ }^{23}$

Our observed trend between use of rehabilitation after stroke and more unmet needs could be explained by the greater level of disability among participants having rehabilitation. Similarly, greater level of disability at 24 months could also explain the observed greater unmet needs among proxy respondents than direct respondents (table e-2).

In Australia, support services are available to community-dwelling survivors. These include services provided by community health centers, GPs, and stroke organizations. ${ }^{24}$ Interventions provided include counseling, monitoring of treatment and recovery, and improving self-management. However, these services are limited by lack of proper coordination to achieve optimal and sustainable benefits, poor individualization of intervention, and poor accessibility to survivors. ${ }^{25}$ Lack of accessible and individualized services, especially for young survivors and those with complex disability, potentially explains our finding and that of others ${ }^{3}$ on the association of younger age ( $<65$ years) and greater level of disability with more unmet needs.

Lack of a coordinated approach could be addressed by providing more comprehensive services that encourage close working relationships among stakeholders involved in care. GPs are well placed to coordinate these services. ${ }^{26}$ This may be particularly beneficial to those at risk of unmet needs such as survivors of stroke/TIA who are young and have greater educational attainment and those with functional disability and mood disorders. Moreover, providing information on local support services (e.g., peer support) at discharge could also benefit these subgroups. ${ }^{7}$
A major limitation of this study is the potential for nonresponse bias in that responders had less disability and potentially fewer unmet needs at the 24month follow-up than nonresponders. However, this bias would have been limited by our good response rate $(81 \%)$. Another potential nonresponse bias could arise from the large proportion of participants (33\%) returning an incomplete survey. We limited this bias by excluding participants with $\geq 10 \%$ of missing outcome data. The observed similarities between models in which missing data were imputed and the unimputed model indicate that this bias is minimal. The observed greater proportion of proxy respondents (than direct respondents) reporting unmet needs suggests that our estimates may have been biased by extreme proxy response, a common phenomenon among caregivers of survivors. ${ }^{27}$ Moreover, recruitment of participants from a clinical trial from one region of Australia limited the generalizability of our findings. However, characteristics of our cohort were similar to those of the general stroke population in Australia. ${ }^{28}$ Generalizability of our results is also limited to countries with similar healthcare systems (e.g., United Kingdom, Canada). Lastly, our questionnaire has not been previously validated in an Australian population, and its construct validity has not been directly ascertained. However, 90\% of items in a questionnaire that was validated in the United Kingdom are consistent with those in our survey. ${ }^{29}$ In addition, most of our survey items have good content validity and consistency with those in previous studies. ${ }^{3,4}$

The main strength of our study is the extensive assessment of unmet needs and incorporation of rare data on survivors of TIA and data on critical aspects of long-term management of stroke. Moreover, compared to previous studies, our assessment of needs followed a more structural approach. ${ }^{15}$ Another strength is the report of rare data on factors associated with unmet needs in survivors of stroke/TIA. Adjusting for these factors in the regression models helped improve the robustness of our estimates.

Our study corroborates findings from previous studies demonstrating considerable long-term unmet needs in survivors of stroke after discharge. These unmet needs were most prominent in the domain of secondary prevention. We also identified factors associated with more unmet needs in survivors of stroke/TIA, especially those related to care and support services available after discharge. Future research should be focused on investigating effective community-based interventions that could help ameliorate these needs. This could help guide policy decisions on how best to support survivors of stroke/TIA in the community. 


\section{AUTHOR CONTRIBUTIONS}

M.T.O.: conceptualization and design of the study, collection of data, analysis and interpretation of data, literature review, and drafting of the manuscript. D.A.C. and J.K.: conceptualization and design of the study, interpretation of data, and critical revision of manuscript for intellectual content. M.R.N.: conceptualization and design of the study and critical revision of manuscript for intellectual content. V.K.S.: conceptualization and design of the study and revision of manuscript for intellectual content. N.E.A.: contribution to the design of the study, analysis and interpretation of data, and critical revision of manuscript for intellectual content. C.F.B., R.P.G., S.M.F., T.P., and J.F.: conceptualization and design of the study and revision of manuscript for intellectual content. A.G.T.: conceptualization and design of the study, supervision of the study, interpretation of data, and critical revision of manuscript for intellectual content. Coinvestigators: Data and Safety Monitoring Committee: Colin Johnston, Julie Bernhardt, Richard Macdonell, and Leonid Churilov.

\section{ACKNOWLEDGMENT}

The authors thank the research nurses for their hard work and dedication.

\section{STUDY FUNDING}

The STANDFIRM trial was funded by the National Health and Medical Research Council (NHMRC) of Australia (586605). A.G.T was supported by NHMRC Senior Research Fellowships (1042600 and 438700). D.A.C and V.K.S were supported by cofunded NHMRC/ National Heart Foundation Career Development Fellowships (1063761, 1061457). M.T. was funded by Monash Graduate Scholarship and Monash International Postgraduate Research Scholarship (24909602). J.K. was funded by the Stroke Foundation Postgraduate Scholarship (PP 10M 5505). The needs survey was funded by the Monash Partners Academic Health Science Centre. Funders had no role in the study design, collection, analysis and interpretation of data, and writing of this manuscript.

\section{DISCLOSURE}

M. Olaiya, D. Cadilhac, J. Kim, M. Nelson, V. Srikanth, N. Andrew, C. Bladin, R. Gerraty, and S. Fitzgerald report no disclosures relevant to the manuscript. T. Phan is a member of the Advisory Board of Genzyme on Fabry Disease and received honoraria for presentations given for Bayer, Boehringer Ingelheim, Genzyme, Pfizer, and BristolMyers Squibb. J. Frayne and A. Thrift report no disclosures relevant to the manuscript. Go to Neurology.org for full disclosures.

Received December 4, 2016. Accepted in final form April 3, 2017.

\section{REFERENCES}

1. Feigin VL, Forouzanfar MH, Krishnamurthi R, et al; Global Burden of Diseases, Injuries, and Risk Factors Study 2010 (GBD 2010) and the GBD Stroke Experts Group. Global and regional burden of stroke during 1990-2010: findings from the Global Burden of Disease Study 2010. Lancet 2014;383:245-254.

2. Deloitte Access Economics. The Economic Impact of Stroke in Australia. Melbourne: National Stroke Foundation; 2013.

3. Andrew NE, Kilkenny M, Naylor R, et al; National Stroke Foundation. Understanding long-term unmet needs in Australian survivors of stroke. Int J Stroke 2014;9:106-112.

4. McKevitt C, Fudge N, Redfern J, et al. Self-reported longterm needs after stroke. Stroke 2011;42:1398-1403.

5. Rittman M, Boylstein C, Hinojosa R, Hinojosa MS, Haun J. Transition experiences of stroke survivors following discharge home. Top Stroke Rehabil 2007;14:21-31.

6. Martinsen R, Kirkevold M, Sveen U. Younger stroke survivors' experiences of family life in a long-term perspective: a narrative hermeneutic phenomenological study. Nurs Res Pract 2012;2012:948791.

7. National Stroke Foundation. Clinical Guidelines for Stroke Management 2010. Melbourne: National Stroke Foundation; 2010

8. Low JT, Kersten P, Ashburn A, George S, McLellan DL. A study to evaluate the met and unmet needs of members belonging to Young Stroke groups affiliated with the Stroke Association. Disabil Rehabil 2003;25: 1052-1056.

9. Andrew NE, Kilkenny MF, Lannin NA, Cadilhac DA. Is health-related quality of life between 90 and 180 days following stroke associated with long-term unmet needs? Qual Life Res 2016;25:2053-2062.

10. Thrift AG, Srikanth VK, Nelson MR, et al. Risk factor management in survivors of stroke: a double-blind, cluster-randomized, controlled trial. Int J Stroke 2014;9:652-657.

11. Dillman DA. The design and administration of mail surveys. Annu Rev Sociol 1991;17:225-249.

12. D'Agostino RB Sr, Vasan RS, Pencina MJ, et al. General cardiovascular risk profile for use in primary care: the Framingham Heart Study. Circulation 2008;117: 743-753.

13. Johnston M, Pollard B, Hennessey P. Construct validation of the Hospital Anxiety and Depression Scale with clinical populations. J Psychosom Res 2000;48:579-584.

14. Harwood RH, Rogers A, Dickinson E, Ebrahim S. Measuring handicap: the London Handicap Scale, a new outcome measure for chronic disease. Qual Health Care 1994;3:11-16.

15. World Health Organization. The International Classification of Functioning, Disability, and Health (ICF). Geneva: Wold Health Organization; 2001.

16. Costello A, Osborne J. Best practices in exploratory factor analysis: four recommendations for getting the most from your analysis. Pract Assess Res Eval 2005;10:1-9.

17. Gardner W, Mulvey EP, Shaw EC. Regression analyses of counts and rates: Poisson, overdispersed Poisson, and negative binomial. Psychol Bull 1995;118:392-404.

18. Kersten P, Low JTS, Ashburn A, George SL, McLellan DL. The unmet needs of young people who have had a stroke: results of a national UK survey. Disabil Rehabil 2002;24: 860-866.

19. Karatepe AG, Gunaydin R, Kaya T, Turkmen G. Comorbidity in patients after stroke: impact on functional outcome. J Rehabil Med 2008;40:831-835.

20. Australian Government Department of Health. Chronic Disease Management: Provider Information. Canberra; 2014. Available at: http://www.health.gov.au/internet/ main/publishing.nsf/content/mbsprimarycare-factsheetchronicdisease.htm. Accessed April 7, 2016.

21. Lurie JD, Berven SH, Gibson-Chambers J, et al. Patient preferences and expectations for care determinants in patients with lumbar intervertebral disc herniation. Spine (Phila Pa 1976) 2008;33:2663-2668.

22. Rickards H. Depression in neurological disorders: Parkinson's disease, multiple sclerosis, and stroke. J Neurol Neurosurg Psychiatry 2005;76:i48-i52.

23. Ngo VK, Rubinstein A, Ganju V, et al. Grand challenges: integrating mental health care into the non-communicable disease agenda. PLoS Med 2013;10:e1001443.

24. Fullerton P, Williams S. Stroke Support Strategy. Melbourne: National Stroke Foundation; 2008. 
25. National Stroke Foundation. National Action Plan for Stroke. Melbourne: National Stroke Foundation; 2012.

26. Harris M, Lloyd J. The Role of Australian Primary Health Care in the Prevention of Chronic Disease. Canberra: Australian National Preventive Health Agency; 2012.

27. Andrew NE, Kilkenny MF, Naylor R, Purvis T, Cadilhac DA. The relationship between caregiver impacts and the unmet needs of survivors of stroke. Patient Prefer Adherence 2015;9:1065-1073.

28. National Stroke Foundation.National Stroke Audit: Acute Services Report 2015. Melbourne: National Stroke Foundation; 2015.

29. LoTS Care LUNS Study Team. Validation of the longerterm unmet needs after stroke (LUNS) monitoring tool: a multicentre study. Clin Rehabil 2013;27:1020-1028.

\section{Save These Dates for AAN CME Opportunities!}

Mark these dates on your calendar for exciting continuing education conferences by the American Academy of Neurology. Learn more at AAN.com/conferences.

\section{Sports Concussion Conference}

- July 14-16, 2017, Jacksonville, FL, at the Hyatt Regency Jacksonville Riverfront

AAN Fall Conference

- October 20-22, 2017, Las Vegas, NV, at The Cosmopolitan of Las Vegas

Breakthroughs in Neurology Conference

- January 12-15, 2018, Orlando, FL, at the Caribe Royale Orlando

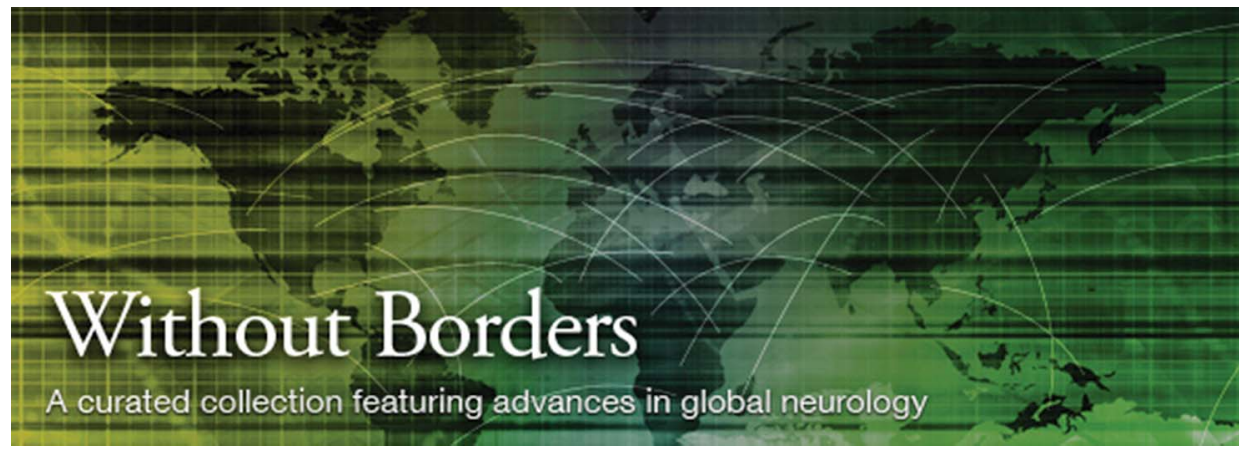

\section{NEW!}

\section{Without Borders - A curated collection featuring advances in global neurology}

This Neurology ${ }^{\circledR}$ special interest Web site is the go-to source for tracking science and politics of neurology beyond the United States, featuring up-to-the-minute blogs, scholarly perspectives, and academic review of developments and research from Neurology journals and other sources. Curated by Gretchen L. Birbeck, MD, MPH.

Expand your world view at Neurology.org/woborders. 